\title{
The Reinforcing Property of Ethanol in the Rhesus Monkey
}

\author{
II. Some Variables Related to the Maintenance of Intravenous Ethanol-Reinforced Responding \\ Andrew J. Karoly*, Gail Winger, Fumio Ikomi**, and James H. Woods \\ Departments of Pharmacology and Psychology, University of Michigan, Ann Arbor, Michigan 48109, U.S.A.
}

\begin{abstract}
Rhesus monkeys received intravenous injections of ethanol during daily sessions contingent on their presses on an available lever. Under the standard conditions, when each response on the lever during a 3 $\mathrm{h}$ period each day resulted in an i.v. injection of $0.1 \mathrm{~g} / \mathrm{kg}$ ethanol, the monkeys made between 30 and 50 responses/session and developed blood ethanol levels of approximately $400 \mathrm{mg} \%$. Under this and other conditions of response-contingent delivery of ethanol, a negatively accelerated pattern of self-injection within sessions was demonstrated. Variations in the dose per injection $(0.05-0.2 \mathrm{~g} / \mathrm{kg} /$ injection) resulted in changes in the rate of lever-pressing; the number of selfinjections was inversely related to dose. Ethanol intake increased only slightly with increased dose per injection. Noncontingent administration of various doses of i.v. ethanol immediately prior to a daily session decreased the number of responses; the total amount of ethanol administered (contingent plus noncontingent), however, remained constant over a pretreatment dose range of 1 to $3 \mathrm{~g} / \mathrm{kg}$. When access time to ethanol was increased from 3 to $6 \mathrm{~h} /$ day, the total amount of ethanol taken increased slightly. However, the blood ethanol levels at the end of a 6-h session closely approximated those obtained following 3 -h sessions, indicating that during the last $3-4 \mathrm{~h}$ of the $6-\mathrm{h}$ sessions, the rate of ethanol intake closely matched the rate of ethanol elimination.
\end{abstract}

Key words: Ethanol - Intravenous self-administration - Tolerance - Rhesus monkey

Operant responding in the rhesus monkey can be maintained by the i.v. delivery of ethanol (Deneau et

\footnotetext{
* Present address: Psychology Department, Humboldt State College, Arcata, California, U.S.A.

** Present address: Department of Pharmacology, Matsumoto Medical School, Matsumoto City, Japan
}

al., 1969; Woods et al., 1971; Winger and Woods, 1973). When monkeys were given unlimited access to ethanol under a schedule in which a single lever-press produced an injection of ethanol, the pattern of ethanol self-injection appeared to be a composite of modulating factors. Some of these factors were related to long-term history (amounts taken over the course of the previous weeks) and others were related to immediate drug history (amounts taken in the last few hours). Episodes of sustained intoxication (approximately $8 \mathrm{~g} / \mathrm{kg} / 24 \mathrm{~h}$ ) occasionally alternated with periods of self-termination of ethanol-reinforced responding. The periods of selftermination, along with the ensuing abstinence syndrome, could be eliminated by restricting ethanol access to a $3-\mathrm{h}$ period in $24 \mathrm{~h}$. This behavioral pattern suggested that the large amounts of ethanol taken over the previous week of unrestricted access to ethanol (long-term history) were responsible for selftermination. Under the limited-access condition, the factors contributed by long-term history were reduced and those related to immediate history became more obvious. A smaller daily intake of ethanol was observed under 3-h access $(3-5 \mathrm{~g} / \mathrm{kg} / 3-\mathrm{h}$ session) than under 24$h$ access. The pattern of self-injection was one of higher rates of responding early in the session and lower rates of responding late in the session, indicating the influence of immediate drug history on current drug intake (Winger and Woods, 1973; Woods et al., 1971).

The purpose of the present experiment was to examine some of the variables related to maintenance of ethanol-reinforced responding under limited access conditions, i.e., situations presumably controlled in part by short-term drug history. Aspects of ethanol delivery were changed by a variety of procedures, and consequent changes in rate and pattern of ethanolreinforced responding were observed. Systematic changes in ethanol dose per injection, ethanol pretreatment, and ethanol access time were assessed with respect to patterns of ethanol-reinforced responding and ethanol intake. In addition, the relation of ethanol- 
reinforced responding to blood ethanol level and its elimination was examined. Finally, ethanol pretreatment was examined in two situations in which ethanol was replaced as a reinforcer by saline (extinction); these extinction conditions were used to determine whether the effect of ethanol served as a cue for further selfinjection responding.

\section{Materials and Methods}

Subjects. Thirteen rhesus monkeys (Macaca mulatta) weighing between 3.5 and $5.5 \mathrm{~kg}$ were allowed at least 5 days in the experimental situation to adapt to the restraint and catheter-protection device. Then, under pentobarbital anesthesia $(30 \mathrm{mg} / \mathrm{kg}$, i.v.), a silicone rubber catheter (insided diameter, $0.08 \mathrm{~cm}$; outside diameter, $0.24 \mathrm{~cm}$; Rodhelm Reiss Co., Belle Mead, New Jersey) was passed through a jugular or femoral vein to the level of the right atrium. Successive jugular or femoral veins were used when the catheter tract became infected or when the animal dislodged the catheter from a vein.

Apparatus. Each monkey was fitted with a stainless steel harness to protect the catheter. The harness was connected to a restraining arm attached to the rear wall of an open-faced cubicle. The extension arm allowed the monkey relatively free movement while restraining it in the $90 \times 75 \times 65 \mathrm{~cm}$ cubicle. The catheter led s.c. through a midscapular stab wound to the harness and then through the tubular restraining arm to an injection pump mounted on the outside rear of the cubicle. A syringe-type injection pump, driven by a reversible motor with a screw shaft, delivered solutions; the volume of the injection was $0.66 \mathrm{ml} / \mathrm{kg}$ of body weight unless otherwise noted. When the injection was completed, the motor reversed, refilling the syringe from a reservoir. For a more complete description of the apparatus and catheterization procedure, see Deneau et al. (1969). The monkeys remained in the cubicles throughout the experiments and were fed Purina Monkey Chow twice daily. Water was continuously available from a pressure nozzle mounted on the back wall.

A lever and a red stimulus lamp were mounted on the rear wall of the cubicle. During illumination of the red light, a lever press of approximately $100 \mathrm{~g}$ activated the injection-refill cycle of the pump. The red light was not illuminated during an injection cycle or during periods when drug was not available.

Individual channels of a strip-chart recorder (Esterline-Angus; Model 190MT) indicated the access periods, each self-administered injection, and lever-press responses. The paper speed allowed visual resolution of individual injections but not individual lever-press responses.

General Procedure. After catheterization the monkeys were exposed to conditions in which each lever press would deliver ethanol $(0.1 \mathrm{~g} / \mathrm{kg} / \mathrm{inj}, 15 \% \mathrm{w} / \mathrm{v}$ dilution in sterile, distilled water from $95 \%$ USP). If the animal failed to initiate responding at $0.1 \mathrm{~g} / \mathrm{kg} /$ injection of ethanol within approximately 10 days, one of three changes was made : either the dose of ethanol was increased to $0.2 \mathrm{~g} / \mathrm{kg} /$ injection; cocaine $(0.3 \mathrm{mg} / \mathrm{kg} / \mathrm{inj})$ was substituted for ethanol; or methohexital $(0.5 \mathrm{mg} / \mathrm{kg} / \mathrm{inj})$ was substituted for ethanol. When responding had been initiated by one of these alternate methods, ethanol at $0.1 \mathrm{~g} / \mathrm{kg} /$ injection was reinstated. Access to ethanol was then either abruptly or gradually reduced to $3 \mathrm{~h}$ every $24 \mathrm{~h}$. See Winger and Woods (1973) for the exact experimental history of three of the monkeys $(289,219,350)$.

Variation of Ethanol Dose per Injection. Two monkeys (289 and 219), which had initiated lever responding with cocaine, and monkey 350 , which had initiated responding with ethanol, were given $3 \mathrm{~h} /$ day access to ethanol $(0.1 \mathrm{~g} / \mathrm{kg} / \mathrm{inj})$. When responding had been main- tained under these conditions for 20 or more sessions, the dose was changed from $0.1 \mathrm{~g} / \mathrm{kg} /$ injection to $0.05,0.075,0.15$, or $0.2 \mathrm{~g} / \mathrm{kg} /$ injection. Each monkey was exposed to a particular dose for at least five 3 -h sessions, and then $0.1 \mathrm{~g} / \mathrm{kg}$ ethanol was reinstated for five or more sessions. The sequence of dose changes from $0.1 \mathrm{~g} / \mathrm{kg} /$ injection ethanol was unsystematic. The concentration of ethanol solution was held constant, and adjustments in volume constituted dose variations. The duration of the injection cycles varied as the volume of the injection was changed.

Ethanol Pretreatment: Ethanol Self-Injection. Three monkeys (258 and 293 cocaine-initiated; 294, ethanol-initiated) were maintained under conditions in which $0.1 \mathrm{~g} / \mathrm{kg} /$ injection ethanol was delivered for each lever-press under $3 \mathrm{~h}$ per $24 \mathrm{~h}$ access. Each monkey had been maintained under these conditions for 15 or more sessions before ethanol or saline pretreatments. Ethanol pretreatment consisted of the administration of a $40 \%(w / v)$ solution of ethanol through the catheter at a rate of $1 \mathrm{ml} / \mathrm{min}$ in a volume equivalent to $1.0,2.0$, or $3.0 \mathrm{~g} / \mathrm{kg}$ immediately before a daily $3-\mathrm{h}$ session. An ethanol pretreatment was repeated at approximately weekly intervals until each monkey had received the three pretreatment doses at least once. On the day before each pretreatment observation, saline was given through the catheter in a volume equivalent to the volume of ethanol administered as a pretreatment on the following day.

Ethanol Pretreatment: Saline Self-Injection. Each of four monkeys (431, cocaine-initiated; C-3, 410, and E-2, ethanol-initiated) was maintained at $0.1 \mathrm{~g} / \mathrm{kg} /$ injection ethanol; three of these monkeys were required to respond on the lever once to produce an injection. The fourth monkey (E-2) was required to respond 30 times to produce an injection. Ethanol access was limited to $3 \mathrm{~h}$ per $24 \mathrm{~h}$ period. When the amount and pattern of ethanol self-injections showed no consistent session-to-session trends, one of the following changes was made for a single 3-h session: (1) saline was substituted for ethanol in the injection pump; (2) in the manner described above, $2 \mathrm{~g} / \mathrm{kg}$ ethanol was administered intravenously immediately before the $3-\mathrm{h}$ session with ethanol remaining in the injection pump; or (3) $2 \mathrm{~g} / \mathrm{kg}$ ethanol was administered immediately before the session with saline substituted for ethanol in the injection pump. These changes were made in an unsystematic order approximately every fourth session. On intervening sessions, ethanol remained in the injection pump, and in all sessions the red light signalling access to the injection-related consequences was illuminated for $3 \mathrm{~h}$ per $24 \mathrm{~h}$.

A subsequent set of observations was made in three of the same four monkeys on the condition of ethanol pretreatment $(2 \mathrm{~g} / \mathrm{kg})$ with saline self-injection. Following restabilization of ethanol-reinforced responding for five or more sessions, a series of 17 sessions was conducted in which saline replaced ethanol in the injection pump during each session. On alternate sessions during this series, $2 \mathrm{~g} / \mathrm{kg}$ of ethanol was administered immediately before the session. A comparative set of observations was made on $2 \mathrm{~g} / \mathrm{kg}$ ethanol pretreatment with saline self-injections, except in this series ethanol remained in the injection pump during non-pretreatment sessions.

Variation of Access Time to Ethanol. Three monkeys (D-1, D-4, E-3) were given $3 \mathrm{~h} /$ day access to ethanol $(0.1 \mathrm{~g} / \mathrm{kg} / \mathrm{inj})$ for 30 or more daily sessions. Access to ethanol was then extended to $6 \mathrm{~h}$ per $24 \mathrm{~h}$ period for over 20 consecutive sessions; 3 -h ethanol access was reinstated for 14 sessions with monkey D-1, 21 sessions with monkey D-4, and 28 sessions with monkey E-3. Monkey E-3 was then observed for 50 additional sessions under $6 \mathrm{~h} /$ day access to ethanol.

Ethanol Blood Levels and Elimination. At various intervals during the study of different access times, blood samples taken after individual sessions were analyzed for ethanol content. For both $3-\mathrm{h}$ and $6-\mathrm{h}$ access condition, this procedure was carried out once for monkey D-1 and twice for monkeys D-4 and E-3. Thus data are an average of five sessions under each access condition. Starting $1 \mathrm{~h}$ after the end of an access period, and at approximately 2 - $h$ intervals thereafter, a $0.2 \mathrm{ml}$ 

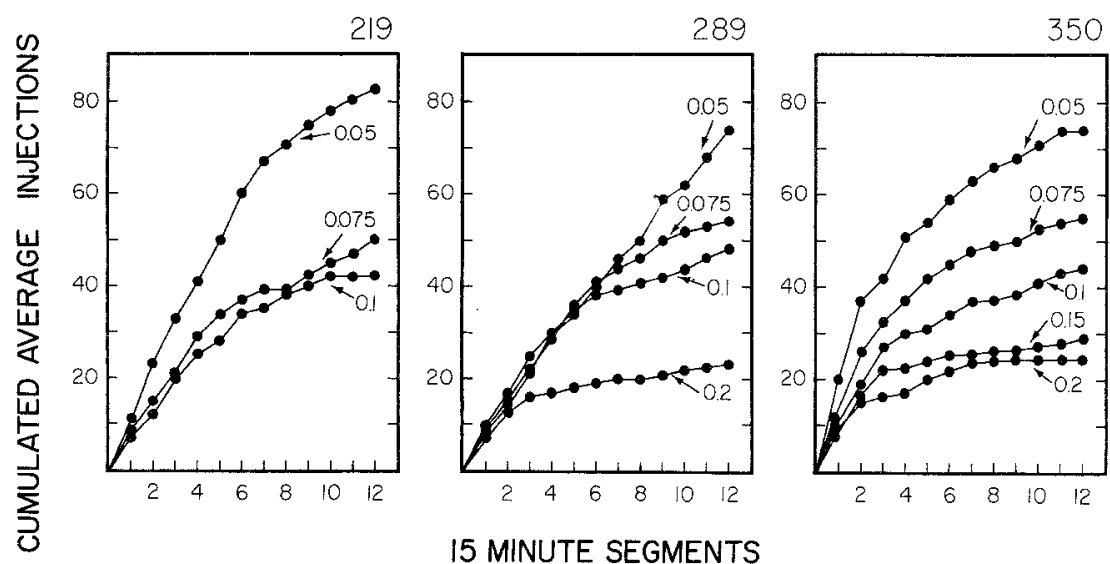

15 MINUTE SEGMENTS

Fig.1. The effects of varying the injection dose of ethanol on patterns of intrasession alcohol injections for monkeys 219,289 , and 350 . Abscissa: number of 15-min segments in a 3-h session; ordinates: cumulative injections received. Injections were cumulated in 15-min segments over a 3-h session and averaged over five consecutive sessions. When more than five sessions were available at a given dose, those used in the figure were randomly selected from those available. The numbers associated with the arrows indicate the ethanol dose $(\mathrm{g} / \mathrm{kg})$ that was administered following each lever response

sample of venous blood was taken from each monkey. Four to eight successive samples were taken from each monkey. Ethanol content of the samples was analyzed in duplicate by an enzymatic method (Bonnichsen, 1963). A linear regression equation was fit by the leastsquares method to the time by $\mathrm{mg} \%$ ethanol data from individual sessions with separate monkeys, and the negative slope of this regression was taken as the rate of elimination of ethanol from the blood. The extrapolated $y$-intercept of this regression function ( $X$ $=0 \mathrm{~h}$; end of access period) was the calculated blood level at the end of the access period.

The blood alcohol accumulating during an access condition was estimated on the days on which elimination rates were obtained. The amount of alcohol taken by the monkey in 15-min segments was determined and this was decreased by the amount of alcohol eliminated during this time (based on the elimination rate found for that monkey on that day). These data were averaged for the five observations.

\section{Results}

Under the most frequently used condition (3-h ethanol access, $0.1 \mathrm{~g} / \mathrm{kg} / \mathrm{inj}$ ), responding resulted in $30-$ 50 injections/session. There was a negatively accelerated rate of ethanol self-injection over the various conditions of ethanol access (Figs. 1, 2, and 4). Responding occurred primarily during periods when ethanol was available, i.e., during the illumination of the red light, but there was considerable responding by the majority of monkeys during the injection-refill cycle. At the end of ethanol sessions, monkeys under all conditions of ethanol self-injection demonstrated clear signs of ethanol intoxication, e.g., motor incoordination, relaxed posture, flushing, and pupil dilation.

Variation of Ethanol Self-Injection Dose. The number of ethanol injections during the 3 -h period was inversely related to the dose delivered with each response over the eightfold range of dose variation investigated (Fig. 1). Each self-injection dose used in these experiments produced a pattern of responding in each monkey that was more rapid at the beginning of the session and slowed as the session progressed. There was a slight tendency for ethanol intake to increase with dose per injection. The average intakes across the three monkeys were $3.9( \pm 0.1) \mathrm{g} / \mathrm{kg}$ at $0.05 \mathrm{~g} / \mathrm{kg} /$ injection; $4.4( \pm 0.1)$ $\mathrm{g} / \mathrm{kg}$ at $0.1 \mathrm{~g} / \mathrm{kg} /$ injection; and $4.7( \pm 0.2) \mathrm{g} / \mathrm{kg}$ at $0.2 \mathrm{~g} / \mathrm{kg} /$ injection.

When the self-injection dose was changed, there was an immediate change in the number of injections, and the adjustment to a changed dose was usually complete within one 3 -h session. Responding maintained by $0.1 \mathrm{~g} / \mathrm{kg} /$ injection ethanol was stable over the course of these observations; there was more variability in the frequency of injections across sessions with smaller doses.

Ethanol Pretreatment: Ethanol Self-Injection. At each of the pretreatment doses, the amount of ethanol selfinjected by a monkey during the 3 -h access period was reduced by the pretreatment amount. Figure $2 \mathrm{a}$ shows the mean intake of ethanol self-injected after each of the three pretreatment doses of ethanol and after saline pretreatment. A regression line fitted to the mean intake after the three pretreatment doses has a slope of -0.997 ; a slope of -1.000 would indicate that ethanol intake was reduced by exactly the dose of ethanol pretreatment.

The effect of ethanol pretreatment on the temporal pattern of self-injection is shown for monkey 258 in Figure $2 \mathrm{~b}$. As can be seen, there was a negatively accelerated pattern of self-injection of $0.1 \mathrm{~g} / \mathrm{kg} /$ injection. This pattern was slightly affected by 


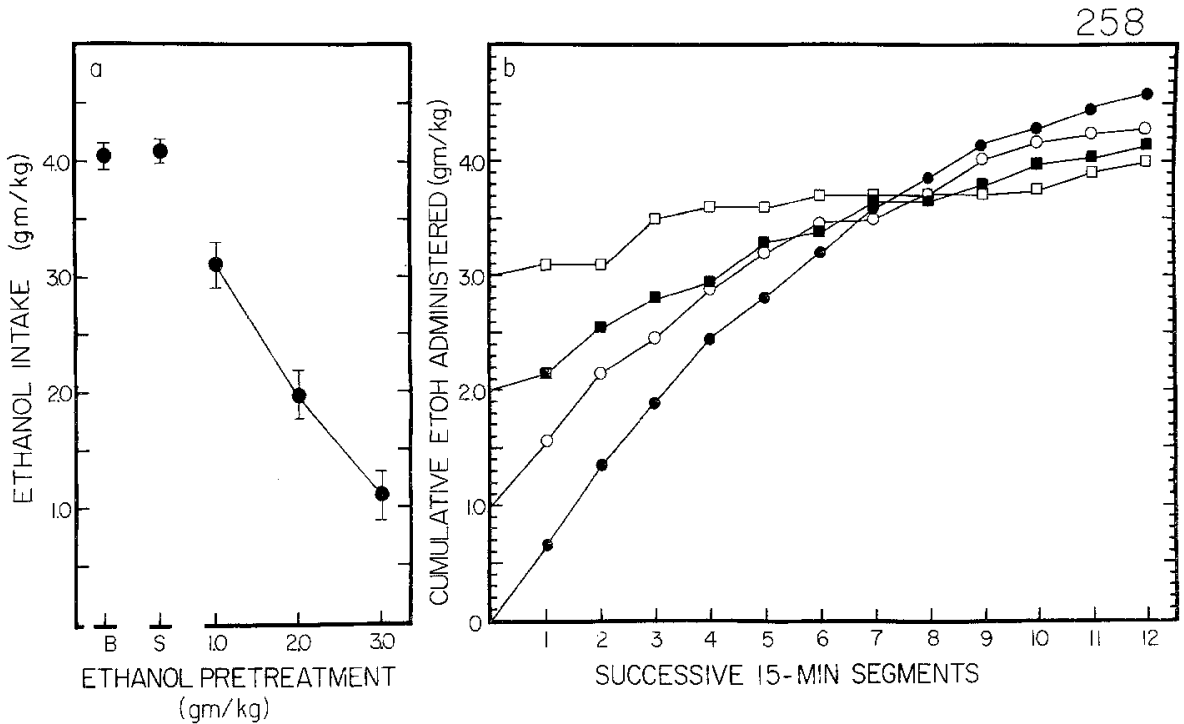

Fig. 2. Effects of various ethanol pretreatment doses on (a) ethanol intake in three monkeys, and (b) pattern of ethanol intake in daily 3-h sessions for monkey 258. In Figure 3a, abscissa: dose of alcohol in $\mathrm{g} / \mathrm{kg}$ given immediately before 3 -h session in which each response on lever resulted in injection of $0.1 \mathrm{~g} / \mathrm{kg}$ ethanol $(\mathrm{S}=$ saline, average ethanol intake following saline injections; $\mathrm{B}=$ baseline, average intake without pretreatment). Each point: mean of at least 4 observations at designated condition. Brackets: \pm 1 SEM. In Figure $2 \mathrm{~b}, a b s c i s s a$ : successive 15 -min segments in $3-$ h session; ordinate: cumulative ethanol administered $(\mathrm{g} / \mathrm{kg})$, i.e., the intake incremented by amount given before session. Pattern of self-injection was averaged over at least three sessions at each pretreatment dose and cumulated in 15 -min segments over 3 -h session. Although data for monkey 258 in Figure $2 \mathrm{~b}$ suggest an inverse relation between alcohol pretreatment dose and total alcohol intake after $3 \mathrm{~h}$, this was not true of other monkeys

1 and $2 \mathrm{~g} / \mathrm{kg}$ alcohol pretreatment doses; $3 \mathrm{~g} / \mathrm{kg}$ alcohol produced a pause, followed by a súall number of injections in the later portion of the session. Thus only at the highest pretreatment dose was there a large change in the temporal pattern of self-injection, even though intake was reduced in a manner directly related to the pretreatment dose.

Ethanol Pretreatment: Saline Self-Injection. The number of ethanol self-injections in these monkeys was substantially equivalent to those previously observed at $0.1 \mathrm{~g} / \mathrm{kg} /$ injection (Table 1). Likewise, the effects of ethanol pretreatment on ethanol self-injection were replicated, i.e., an ethanol pretreatment of $2 \mathrm{~g} / \mathrm{kg}$ reduced the intake of self-injected ethanol by approximately $2 \mathrm{~g} / \mathrm{kg}$ (Table 1). During the sessions in which saline was substituted for ethanol in the injection pump, the number of self-injections was reduced substantially in two (E-2 and 410) of the four monkeys. Ethanol pretreatment markedly increased the number of saline self-injections taken by E- 2 and 410 and may have had less of a decreasing effect on the saline self-injection responding of 431 and $\mathrm{C}-3$ than on the ethanol selfinjection responding. Ethanol did not, however, increase saline self-injections in these two monkeys whose rates of saline intake were not lower than those of ethanol intake.

The effect of $2 \mathrm{~g} / \mathrm{kg}$ of ethanol pretreatment given on alternate days under conditions of saline self-
Table 1. The effect of ethanol pretreatment $(2 \mathrm{~g} / \mathrm{kg})$ on the number of ethanol or saline self-injections

\begin{tabular}{|c|c|c|c|c|}
\hline \multirow[t]{3}{*}{ Monkey } & \multicolumn{4}{|c|}{ Injection solution } \\
\hline & \multicolumn{2}{|l|}{$\begin{array}{l}\text { Ethanol } \\
0.1 \mathrm{~g} / \mathrm{kg} / \mathrm{inj}\end{array}$} & \multicolumn{2}{|l|}{ Saline } \\
\hline & Control & $\begin{array}{l}2 \mathrm{~g} / \mathrm{kg} \\
\text { ETOH } \\
\text { pretreat- } \\
\text { ment }\end{array}$ & Control & $\begin{array}{l}2 \mathrm{~g} / \mathrm{kg} \\
\text { ETOH } \\
\text { pretreat- } \\
\text { ment }\end{array}$ \\
\hline $\mathrm{E}-2$ & $41.4^{\mathrm{a}}$ & $24.7^{\mathrm{b}}$ & $19.7^{\mathrm{b}}$ & $44.0^{\mathrm{b}}$ \\
\hline 410 & 43.4 & 21.3 & 17.3 & 46.7 \\
\hline 431 & 37.1 & 25.0 & 45.0 & 33.3 \\
\hline $\mathrm{C}-3$ & 35.9 & 18.0 & 30.3 & 28.3 \\
\hline Average & $39.4 \pm 1.8^{c}$ & $22.2 \pm 1.6^{\mathrm{d}}$ & $28.1 \pm 6.3^{\mathrm{d}}$ & $38.1 \pm 4.3$ \\
\hline
\end{tabular}

a Average based on ten sessions

b Average based on three sessions

- Average and \pm 1 SEM based on 40 observations

d Average and \pm 1 SEM based on 12 observations

injection was then studied. When saline was available for self-injection throughout the series (i.e., on both ethanol pretreatment days and non-treatment days), the effect of ethanol pretreatment was to increase the number of saline self-injections. This rate-increasing effect of ethanol decreased thoughout the 17-day series, as did the number of saline self-injections in the absence 
Fig. 3

The effects of chronic ethanol pretreatment on saline self-injection when, on alternate 3 -h sessions, (a) saline injections or (b) ethanol injections were response consequence. In Figure $3 a$, conditions of first five sessions were $0.1 \mathrm{~g} / \mathrm{kg}$ ethanol self-injection and data points (closed squares) are number of injections received. On sixth and subsequent sessions, saline replaced ethanol in injection pump. On evennumbered sessions (closed circles), there were no pretreatments given. On odd-numbered sessions (open circles), ethanol $(2 \mathrm{~g} / \mathrm{kg})$ was administered just before session. In Figure $3 b$, first five sessions were the same as in Figure 3a; viz., each lever response was followed by i.v. delivery of $0.1 \mathrm{~g} / \mathrm{kg} /$ injection ethanol. This condition continued on even-numbered sessions from session 6 through 22 . On odd-numbered sessions, saline was substituted for ethanol in injection pump and a $2 \mathrm{~g} / \mathrm{kg}$ ethanol pretreatment was administered just before the sessions. Points based on average of individual observations in four monkeys (Fig. 3a) or three monkeys (Fig. 3b)

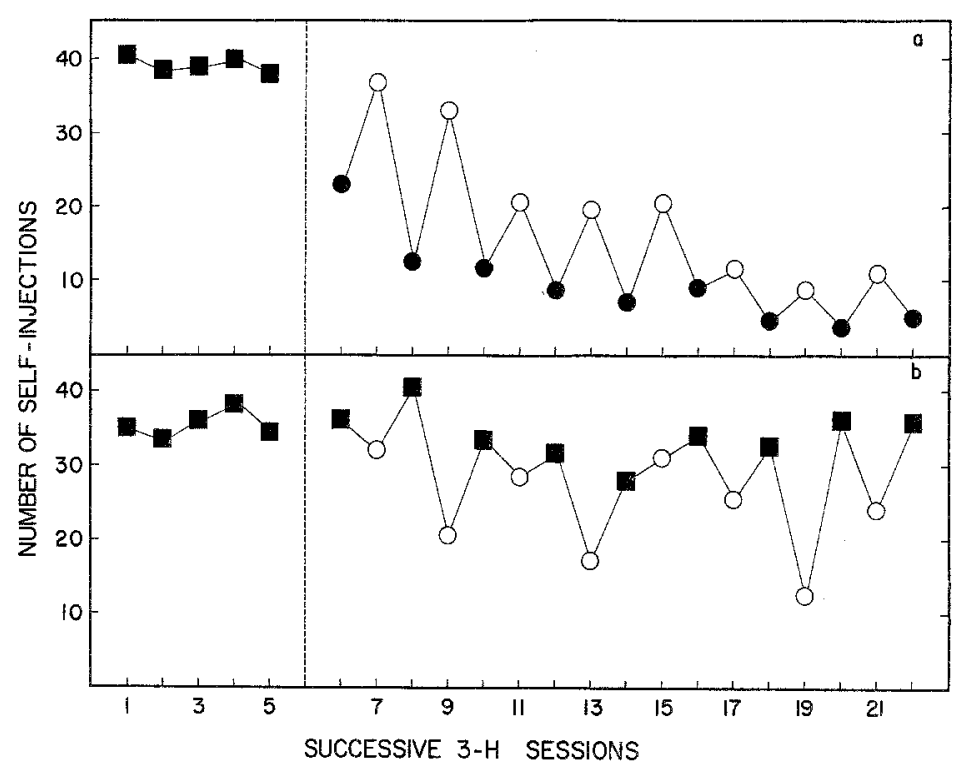

of ethanol pretreatment (Fig. 3a). When ethanol rather than saline was available for self-injection on nonpretreatment days, the effect of ethanol pretreatment on saline self-injection was more variable (Fig. 3b). The number of saline self-injections following ethanol pretreatment was consistently less than the number of ethanol self-injections (Fig. $3 \mathrm{~b}$ ), but usually greater than the number of saline self-injections taken in the absence of ethanol pretreatment as shown in the earlier series (Fig. 3a). Also, the effect of ethanol pretreatment on saline self-injections was maintained over the series in which ethanol was available on alternate days, as opposed to the gradually decreasing effect seen when saline was available on alternate days.

Variation of Access Time to Ethanol. Ethanol intake under 6-h access was about $1 \mathrm{~g} / \mathrm{kg} /$ session higher than under 3-h access (Table 2; Fig. 4, insets). As with the other monkeys and other conditions, ethanol intake in these monkeys was a negatively accelerated function of access time.

Ethanol Blood Levels and Elimination Rates. Ethanol blood levels were closely related to amount of ethanol taken under 3-h access conditions (Table 2 and Fig. 4). The average elimination rate was approximately $30 \mathrm{mg} \% / \mathrm{h}$ and was similar under both 3 -h and $6-\mathrm{h}$ access conditions (Fig. 4). Although there was approximately a $20 \%$ increase in session ethanol intake under 6-h access as compared to 3-h access for ethanol, there was a $6 \%$ increment in blood ethanol level (Table 2).

The calculated time functions of blood ethanol for the two access conditions are presented in Figure $4 a, b$.
Table 2. Means and standard errors of ethanol intake, end-of-session blood level, and elimination rate from the blood under three- and sixhour access

\begin{tabular}{|c|c|c|c|}
\hline Monkey & & 3 -h access & 6-h access \\
\hline & & \multicolumn{2}{|c|}{ Ethanol intake $(\mathrm{g} / \mathrm{kg})$} \\
\hline D-1 & & $4.4 \pm 0.5^{\mathrm{a}}$ & $5.0 \pm 0.3$ \\
\hline $\mathrm{D}-4$ & & $3.7 \pm 0.2$ & $4.8 \pm 0.1$ \\
\hline \multirow[t]{3}{*}{ E-3 } & & $3.9 \pm 0.2$ & $4.9 \pm 0.2$ \\
\hline & Average & $4.0 \pm 0.2$ & $4.9 \pm 0.2$ \\
\hline & & \multicolumn{2}{|c|}{ Ethanol blood level ( $\mathrm{mg} \%$ ) } \\
\hline D-1 & & $424 \pm 56^{b}$ & $405 \pm 22$ \\
\hline D-4 & & $394 \pm 22$ & $445 \pm 15$ \\
\hline \multirow[t]{3}{*}{$E-2$} & & $392 \pm 32$ & $449 \pm 17$ \\
\hline & Average & $405 \pm 23$ & $431 \pm 11$ \\
\hline & & \multicolumn{2}{|c|}{ Ethanol elimination rate $(\mathrm{mg} \% / \mathrm{h})$} \\
\hline D-1 & & $33.6 \pm 3.2^{b}$ & $30.0 \pm 1.6$ \\
\hline D-4 & & $33.4 \pm 2.6$ & $39.7 \pm 2.1$ \\
\hline \multirow[t]{2}{*}{$\mathrm{E}-3$} & & $31.2 \pm 3.9$ & $35.5 \pm 1.1$ \\
\hline & Average & $32.8 \pm 1.8$ & $34.7 \pm 1.4$ \\
\hline
\end{tabular}

a Average of four or more observations, \pm 1 SEM

b Blood levels and elimination rates are from the same sessions as those for which intake is given

The increasing limb of each function shows how blood levels increased during alcohol intake under the two access conditions. These data were calculated for $15-$ min segments in each of the three monkeys as described 


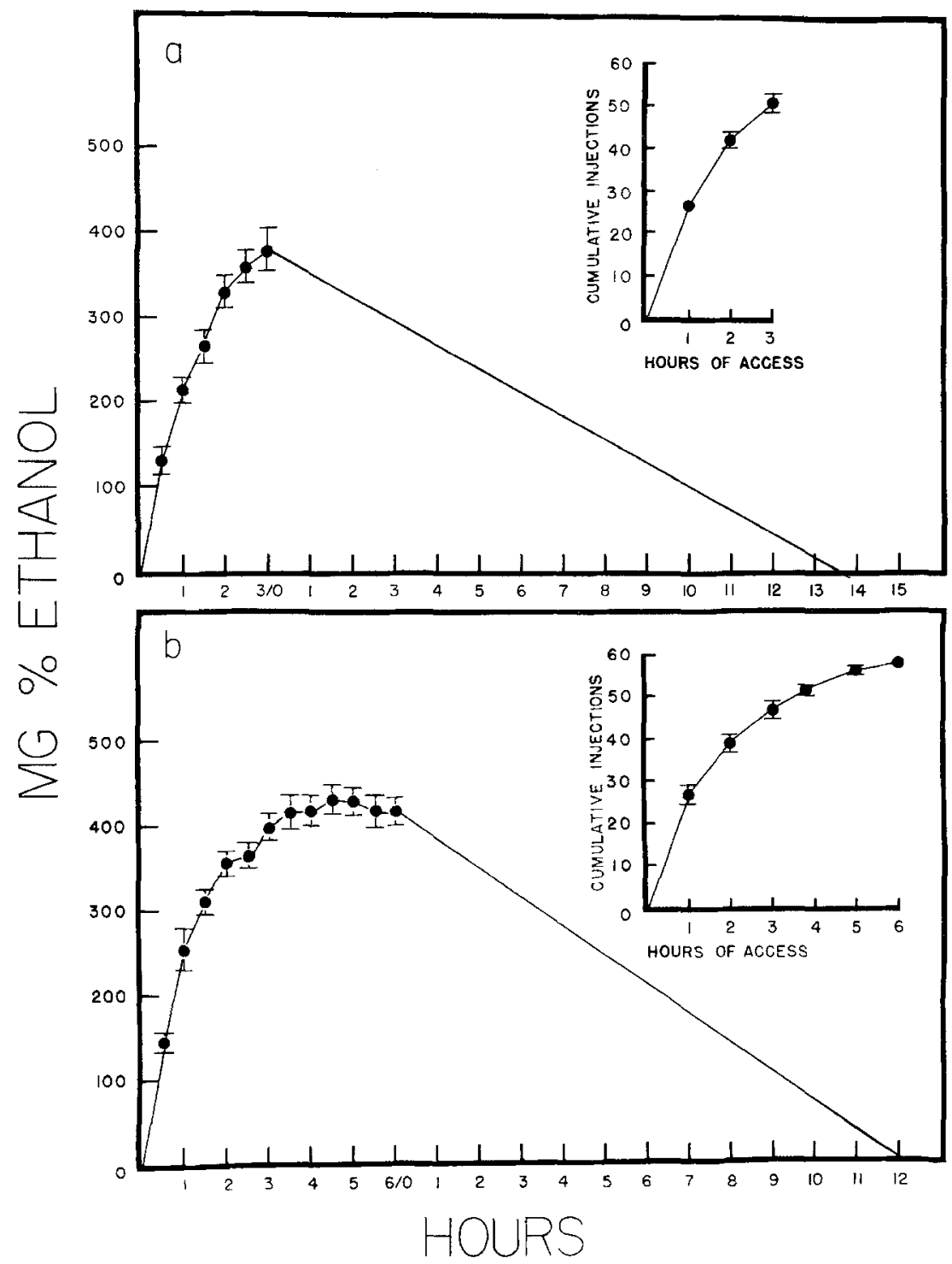

Fig. 4. The effect of (a) 3-h and (b) 6-h ethanol access on cumulative injections of $0.1 \mathrm{~g} / \mathrm{kg}$ ethanol (insets) and cumulation and elimination functions of blood ethanol under these conditions. Ethanol blood level curves based on 5 observations. Average elimination rate was $27.2 \mathrm{mg} \% / \mathrm{h}$ under 3-h access, and $34.2 \mathrm{mg} \% / \mathrm{h}$ under 6-h access. Average SEs of estimates for individual elimination functions were $5.4 \mathrm{mg} \% / \mathrm{h}$ for $6-\mathrm{h}$ access, and $6.9 \mathrm{mg} \% / \mathrm{h}$ for $3-\mathrm{h}$ access $(N=15)$. Points for ethanol blood levels are averaged cumulated blood ethanol as estimated from elimination data; brackets indicate $\pm 1 \mathrm{SE}$

in Materials and Methods. The points are averages of five observations at each time period. This acquisition function has a positive slope when the monkeys injected more ethanol in a given time interval than they could eliminate in that same time. A constant blood ethanol level was maintained by response rates that produced intake equivalent to elimination rate. This "condition of equilibrium' occurred during the last $2-3 \mathrm{~h}$ of the $6-\mathrm{h}$ access period (Fig. 4b).

The decreasing limbs of this figure represent the average of the five elimination functions obtained in the three monkeys.

\section{Discussion}

Increases in the ethanol dose per injection, the number of hours per day of access to ethanol, and the pretreatment dose of ethanol all had in common the effect of reducing the rate of ethanol-reinforced responding. The reduction in response rates was an approximate compensation for these increases in ethanol dose so that total 3-h intake remained nearly the same across several pretreatment doses and doses per injection. Likewise, the decreased response rate in the last half of the $6-\mathrm{h}$ session resulted in end-of-session blood ethanol levels 
that were only slightly higher than those obtained after 3 -h sessions. This suggests that a common negative feedback (rate-decreasing) effect of ethanol modulated the reinforcing effect in each of these experimental manipulations. A given amount of ethanol thus had a similar rate-decreasing effect on ethanol intake whether it was passively received, actively self-injected in smaller or larger increments, or self-injected over shorter or longer sessions.

The accumulation of ethanol in blood within a session appeared to correlate well with ethanol's ratereducing effect. When accumulation reached about $400 \mathrm{mg} \%$, the monkey was in a state of sufficient intoxication so that it self-injected only a small amount of ethanol, sufficient to maintain a metabolic equilibrium (Figs. 2 and 4). This level of $400 \mathrm{mg} \%$ may represent the point at which the rate-decreasing effects of ethanol were titrated equally with the rate-increasing effects in this situation. Yokel and Pickens (1974) reported similar results using rats that self-injected amphetamine. Whole body levels and blood levels of amphetamine remained relatively constant despite changes in the injection dose and changes in absolute intake. The rate-decreasing effect of ethanol in these experiments was specific to rates maintained by ethanol itself. When ethanol was given to monkeys in an amount that had reduced ethanol-reinforced responding, rates of saline self-injections actually increased under some conditions.

Ethanol pretreatment resulted in maintained saline self-injections when ethanol had recently served as a reinforcer in the situation, but not otherwise. If the effect of ethanol pretreatment on saline self-injection was evaluated as a single-session probe (Table 1) or in sessions that alternated with those in which ethanol served as a reinforcer (Fig. $3 b$ ), saline self-injection rates were frequently as high as those of ethanol selfinjection rates, and showed no consistent trend toward declining. In contrast, ethanol pretreatment gradually lost its ability to increase saline self-injection when ethanol was no longer available as a reinforcer (Fig. 3a). In this situation, the response-contingent delivery of ethanol may produce conditions that establish the drug as a discriminative stimulus as well as a reinforcer. Its strength as a discriminative stimulus should decrease when ethanol is no longer responsecontingent (Fig. 3 a) and should be relatively wellmaintained as long as ethanol continues to be available as a reinforcer (Table 1 and Fig. 3 b). Ethanol has been shown to function as a discriminative stimulus in experimental situations in which responding is maintained by nondrug reinforcers (e.g., Barry and
Krimmer, 1977; Overton, 1972). Likewise, it has been shown that environmental events that repeatedly occur in association with stimuli that increase drugreinforced responding can become conditioned stimuli themselves. Such discriminative stimuli may bring about increases in drug-reinforced responding (Goldberg et al., 1969). Thus these data on ethanol pretreatments suggest that ethanol may serve as a discriminative event in situations involving ethanol self-injection. Both this function and the reinforcing function, then, represent rate-increasing effects of ethanol.

Acknowledgements. Research supported by USPHS Grant DA 00154 and AA 02644 . G.W. was a predoctoral trainee supported by USPHS Grant NB 01311. Both A.K. and F.I. were postdoctoral fellows: A.K. was supported by NSF GY8525 in Psychology and F.I. was supported by a Miles Laboratory Fellowship in Pharmacology. A portion of this paper is based on part of a dissertation, submitted to Rackham School of Graduate Study, University of Michigan, by G.W. in partial fulfillment of the requirements for the Ph.D. degree in Psychology. A preliminary report of some of these results appeared in Woods, Ikomi, and Winger (1971).

We thank Ms. D. Schmalgemeier for excellent technical assistance with the experiments and Dr. C. C. Hug for assistance on bloodlevel assessment.

\section{References}

Barry, H., III, Krimmer, E. C.: Discriminable stimuli produced by alcohol and other CNS depressants. In: Discriminable stimulus properties of drugs, H. Lal, ed., pp. 73-92. New York: Plenum Press 1977

Bonnichsen, R.: Ethanol determination with alcohol dehydrogenase and DPN. In: Methods of enzymatic analysis, H. U. Bergmeyer, ed., pp. 285-287. New York: Academic Press 1963

Deneau, G. A., Yanagita, T., Seevers, M. H.: Self-administration of psychoactive substances by the monkey: a measure of psychological dependence. Psychopharmacologia (Berl.) 16, 30-48 (1969)

Goldberg, S. R., Woods, J. H., Schuster, C. R. : Morphine: conditioned increases in self-administration in rhesus monkeys. Science 166, 1306 (1969)

Overton, D. A. : State dependent learning produced by alcohol and its relevance to alcoholism. In: The biology of alcoholism, vol. 2, physiology and behavior, B. Kissin and H. Begleiter, eds., pp. 193-217. New York: Plenum Press 1972

Winger, G. D., Woods, J. H.: The reinforcing property of ethanol in the rhesus monkey. I. Initiation, maintenance and termination of intravenous ethanol-reinforced responding. Ann. N,Y. Acad. Sci. 215, 162-175 (1973)

Woods, J. H., Ikomi, F, Winger, G.: The reinforcing property of ethanol. In: The biological aspects of alcohol, M. K. Roach, W. M. McIsaac, and P. J. Creaven, eds., pp. 371-388. Austin: University of Texas Press 1971

Yokel, R. A., Pickens, R.: Drug levels of $d$ - and $l$-amphetamine during intravenous self-administration. Psychopharmacologia (Berl.) 34, 255-264 (1974)

Received January 17, 1977; Final Version December 20, 1977 